\title{
Análise de Estilo Dinâmica de Fundos Multimercados: Aplicação para o Mercado Brasileiro
}

\author{
Dynamic Style Analysis of Brazilian Hedge Funds \\ Isabel Gaio Schutt* \\ João Frois Caldeira**
}

\begin{abstract}
Resumo: Este artigo aplica o modelo de análise de estilo baseado em retornos (RBSA) considerando explicitamente a presença de exposiçōes variantes no tempo. Inicialmente, o modelo é estimado assumindo que os estilos săo constantes ao longo do tempo. Posteriormente, é utilizada a abordagem do filtro de Kalman para modelar as exposiçōes dos fundos multimercados variantes ao longo do tempo. Usando uma base de dados de fundos multimercados brasileiros, os resultados mostram que a RBSA pode explicar mais de $50 \%$ da variância dos retornos dos fundos. Também evidencia significante exposição ao mercado de ações e que a exposição a fatores relacionados ao mercado de renda fixa vem crescendo. Finalmente, a modelagem considerada capta mudanças importantes no estilo de exposição a fatores de risco dos fundos multimercados brasileiros decorrentes da recente crise financeira global (2008-2009).
\end{abstract}

Palavras-chave: Análise de estilo dinâmica. Filtro de Kalman. Parâmetros variantes no tempo. Fundos multimercados. Persistência.

Abstract: This paper applies the traditional return-based style analysis (RBSA) in the presence of time-varying exposures. Often the investment style is assumed to be constant through time. Alternatively, time variation is sometimes implicitly accounted for by using rolling regressions when estimating the style analysis. We use the Kalman filter to model time-varying exposures of hedge funds explicitly. This leads to a testable model and more efficient use of the data, which reduces the influence of spurious correlation between hedge fund returns and style indices. The aim of this study is to estimate the investment styles and reveal periodic return distributions of Brazilian hedge funds for the 20062011 period. In a large sample of funds, we find substantial evidence that hedge fund risk exposures vary along the time. We also find that the exposition to fixed income is increasing over the last years. The results have shown that style analyses explain over $50 \%$ of the funds returns. Finally, we analyze exposures during the global financial crisis (2008-2009).

Keywords: Dynamic style analysis. Kalman filter. Time varying parameter. Hedge funds. Persistence.

JEL Classification: C53; E43; G17.

- Especialista em Economia e Finanças pelo PPGE da Universidade Federal do Rio Grande do Sul. Gerente de riscos do Banco Sicredi S.A. E-mail: isabel schutt@sicredi.com.br

* Professor do Departamento de Economia e Relaçōes Internacionais da Universidade Federal do Rio Grande do Sul. E-mail: joao.caldeira@ufrgs.br

$\mathrm{O}$ autor agradece ao CNPq pelo auxílio financeiro oferecido através dos processos $n^{\circ}$ 309899/2015-0 e 485561/2013-1.

SCHUTT, I, G.; CALDEIRA, J. F. Análise de Estilo Dinâmica de Fundos Multimercados... 


\section{Introdução}

Uma parcela relevante de investidores ao redor do mundo aplica seus recursos no mercado financeiro através de fundos de investimento. Esse veículo de investimento permite ao investidor aplicar seus recursos em uma carteira de ativos constituída sob a forma de um condomínio fechado com a comunhão de bens de diversos investidores, a qual será administrada por profissionais do mercado financeiro. Uma das grandes vantagens para o investidor ao realizar suas aplicaçōes via um fundo de investimento é justamente diversificar a alocação de seus recursos sem precisar acompanhar o mercado financeiro diariamente. Assim, ao invés de avaliar ativos disponíveis no mercado e suas possíveis combinaçôes, o investidor avalia os fundos de investimento oferecidos por instituições especializadas na gestão de recursos.

O universo dos fundos de investimento, principalmente os multimercados, contém um amplo espectro de estilos que diferem no que diz respeito aos objetivos de performance, ativos financeiros e estratégias de trading adotadas pelos gestores quando montam e administram suas carteiras, sendo que as diferenças de estilo de investimento, ou diferentes exposiçöes aos fatores de risco, podem explicar boa parte da variação cross-sectional nos retornos dos fundos de investimento (BARBERIS; SHLEIFER, 2003; CHAN et al., 2002; FUNG et al., 2005; GIBSON; GYGER, 2007; MARTIN, 2009; PATTARIN et al., 2004).

Investidores racionais buscam alcançar um equilibrio aceitável entre as condições de risco e retorno. Nesse sentido, a alocação estratégica de ativos é de grande importância na gestão de portfólios, e o estabelecimento de um equilíbrio depende da constituiçăo de uma combinaçăo eficiente de ativos. No entanto, com frequência muitos investidores, e mesmo a imprensa especializada, comparam simplesmente os retornos realizados de fundos de investimento sem levar em conta as diferenças na sua exposição.

Em função do grande número de fundos multimercados existentes hoje em dia, é quase impossível para o investidor identificar de forma adequada o estilo de investimento de um fundo específico. Dessa forma, para que o investidor tenha as informaçōes necessárias para decidir qual fundo de investimento é mais adequado ao seu perfil de risco e retorno é importante dispor de ferramentas que permitam identificar as características e as exposições a fatores de risco de cada fundo.

Investidores e especialistas em finanças podem obter estimativas a respeito da exposição dos fundos de investimentos através da análise de estilo, modelo introduzido inicialmente por Sharpe $(1992,1998)$ e generalizado por Agarwal e Naik (2000), Agarwal (2004) e Fung e Hsieh (2002). O método proposto por Sharpe ficou conhecido como análise de estilo baseada nos retornos (return-based style analysis - RBSA), que é basicamente uma regressão restrita dos retornos dos fun- 
dos sobre os fatores de risco relevantes no mercado. $O$ modelo pode ser usado como uma ferramenta valorosa para investidores e consultores na estimação da exposição de fundos de investimentos e na verificação de quão bem os gestores cumprem os objetivos de investimentos estabelecidos. A análise de estilo pode desempenhar ainda um papel fundamental ao inferir as exposiçóes de fundos multimercados aos fatores de risco, ajudando a classificá-los e a determinar benchmarks apropriados para avaliar sua performance.

Assim, para um potencial investidor de fundos multimercados, o modelo de análise de estilo introduzido por Sharpe (1992) é uma forma simples e objetiva de obter uma primeira impressáo sobre o histórico de exposição de um fundo (TRZCINKA, 2001). Nesse sentido, o modelo RBSA teve amplo impacto e implicações do ponto de vista prático (TRZCINKA, 2001), se tornando uma ferramenta bastante popular na análise de fundos de investimento. Diversos autores apontam pontos fracos e sugerem adequaçōes ao modelo original. Por exemplo, Swinkels e Sluis (2006), Christopherson e Trittin (1995) e Dibartolomeo e Witkowski (1997) destacam que um dos pontos fracos da RBSA na sua versão original é a hipótese de que o estilo de investimento de um fundo se mantém fixo ao longo do tempo. A crítica básica é que as exposiçöes aos fatores de risco estimadas com base em dados históricos são instáveis e que é difícil capturar o estilo quando o gestor pode mudar de estratégia de investimento.

Neste artigo considera-se explicitamente a variação ao longo do tempo no estilo de investimento de um gestor de fundos multimercados. O modelo RBSA é colocado no formato de estado-espaço e as exposições dos fundos aos fatores de risco são tratadas explicitamente como variantes ao longo do tempo. Utilizando o filtro de Kalman, toda a amostra é usada para estimar as exposiçóes em cada ponto do tempo. Consequentemente, não é necessário definir um tamanho para a janela de estimaçāo, pois o filtro de Kalman determina de forma ótima o peso de cada informação em determinada exposição. Com as estimativas das exposições variantes ao longo do tempo, é possível, além de identificar os estilos de investimento dos fundos, verificar a persistência das exposições ao longo do tempo.

Utilizando uma ampla base de dados composta por 388 fundos multimercados brasileiros para o período de janeiro de 2006 a outubro de 2011 , os resultados encontrados sugerem que os fundos multimercados brasileiros apresentam significativa exposição positiva ao mercado de açōes e a fatores relacionados a títulos de renda fixa. Em geral, a análise de estilo pode explicar até $50 \%$ da variância dos retornos dos fundos multimercados. Fica evidente também a importância de se considerar a dinâmica das exposiçōes na análise de estilo. Além disso, percebe-se que as maiores oscilaçōes ao longo do tempo são verificadas na exposição ao fator de risco relacionado ao mercado de açōes, que diminuiu de forma considerável, principalmente a partir de 2008. 
Nesse sentido, este artigo contribui para a literatura de duas formas: primeiro, a RBSA é aplicada pela primeira vez a uma ampla base de fundos multimercados brasileiros, incluindo o período da crise financeira deflagrada em 2008; posteriormente, o modelo é colocado no formato de estado-espaço e os parâmetros (exposições dos fundos aos fatores de risco) são estimados como variantes no tempo através do filtro de Kalman. Assim, as exposiçōes dos fundos multimercados aos fatores de risco sảo tratadas explicitamente como variantes no tempo, o que permite analisar a sua persistência ao longo do período considerado.

Além desta introduçāo, o presente trabalho traz mais cinco seçōes: a seção 2 apresenta uma revisão da literatura; a seção 3 realiza uma breve descrição da indústria de fundos multimercados no Brasil; a seção 4 mostra o modelo na forma estado-espaço; a seção 5 apresenta e discute a base de dados utilizada e destaca os resultados empíricos e sua discussão; e, por último, a seção 6 finaliza com as consideraçōes finais.

\section{Revisão da Literatura}

O modelo RBSA de Sharpe, conhecido como modelo de fatores para classes de ativos, partiu do fundamental teórico de modelos de fatores (FUNG; HSIEH, 1997) e demonstrou empiricamente que apenas um número limitado de classes de ativos foi necessário para replicar com sucesso o desempenho de um amplo conjunto de fundos de investimento nos Estados Unidos. A RBSA proposta originalmente por Sharpe $(1992,1998)$ consiste basicamente em um processo investigativo a respeito da composição da carteira de um fundo de investimento. $O$ método proposto por Sharpe (1992) envolve a análise dos retornos dos fundos em relação aos fatores de risco apropriados. As exposiçōes estimadas são indicativos do estilo dos fundos (Dor et al., 2006). Mais especificamente, o trabalho analisa a forma como o retorno de um fundo se movimenta junto com o retorno das classes de ativos, utilizando o resultado para estimar a alocação efetiva do mix de ativos ou o estilo do fundo.

Outra contribuição chave dessa abordagem, conforme o próprio autor explica, está na possibilidade de separar o retorno de uma carteira em dois componentes: um componente relacionado ao estilo, representado pelos fatores explicativos, e outro componente relacionado à seleção de ativos atribuída ao termo residual. Conforme destacado por Sharpe, em uma carteira bastante diversificada o risco idiossincrático se reduz fortemente $e$ a parte do retorno atribuída ao estilo se torna ainda mais expressiva, enfatizando a utilidade do modelo. Dado que o estilo de investimento de um fundo nem sempre é claro para os investidores, Sharpe (1992) argumenta, ainda, que o modelo pode ser útil também na avaliação do desempenho dos fundos, pois fornece um meio para construção de benchmarks. Em outras 
palavras, a análise de estilo pode desempenhar um papel fundamental ao inferir as exposiçōes aos fatores de risco dos gestores, ajudando a classificá-los e a determinar um benchmark adequado para avaliar sua performance.

O modelo proposto por Sharpe foi amplamente difundido e a RBSA se tornou uma ferramenta bastante popular na análise de fundos de investimento. No entanto, Fung e Hsieh (1997) afirmam que a análise de estilo tal como proposta por Sharpe não alcança o mesmo sucesso quando aplicada a hedge funds, isso porque o retorno dos hedge funds é determinado por no mínimo dois componentes: o retorno dos ativos que compōem a carteira, e a dinâmica das estratégias adotadas. Fung e Hsieh (1997) argumentam que o modelo de Sharpe foca apenas no primeiro fator. ${ }^{1} \mathrm{Em}$ outras palavras, o modelo RBSA não leva em conta que as exposiçōes em cada estratégia podem se alterar rapidamente dadas as oportunidades no mercado. Além disso, as restrições impostas no modelo impedem que os fundos tenham posiçōes vendidas ou alavancadas, características usuais dos hedge funds.

Seguindo os trabalhos de Sharpe (1992, 1998) e Fung e Hsieh (1997), muitos autores buscam analisar as exposições de hedge funds regredindo seus retornos contra fatores de risco, por exemplo: Agarwal e Naik (2000), Brown (2001), Mitchell e Pulvino (2001) e, mais recentemente, Corielli e Meucci (2004), Otten e Bams (2004), Horst et al. (2004), Swinkels e Sluis (2006), Lau (2007), Bodson et al. (2010), Pojarliev e Levich (2010), Weng e Trück (2011) e Jawadi e Khanniche (2012), entre outros.

A RBSA convencional impōe restriçōes quanto à venda de ativos a descoberto e também que os pesos das exposições aos fatores de risco somem um, 0 que limita a aplicação do modelo a hedge funds. Alternativamente, Agarwal e Naik (2000) rotulam a RBSA sem essas restriçōes de análise de estilo generalizada, possibilitando estimar as exposiçöes de hedge funds aos fatores de risco de forma mais robusta, já que esses veículos de investimento podem assumir posições alavancadas e realizar vendas a descoberto. Brown (2001) implementa uma abordagem usando o histórico de retornos e os estilos informados pelos gestores e encontra evidências de que as diferenças no estilo de investimento explicam aproximadamente $20 \%$ da variabilidade cross-sectional na performance dos hedge funds. Vestergren (2009) aplica RBSA generalizada a fundos suecos e encontra que aproximadamente $92 \%$ da variação dos retornos ao longo do tempo é explicada pelos estilos dos fundos. A literatura sobre modelagem de retornos de hedge funds usando modelos estáticos é extensa. Uma lista parcial inclui também Ackermann

I Anson (2002) e Amin e Kat (2003) argumentam que os retornos de fundos multimercados săo substancialmente mais complexos do que retornos de títulos de renda fixa ou do mercado de açóes.

SCHUTT, I, G.; CALDEIRA, J. F. Análise de Estilo Dinâmica de Fundos Multimercados... 
et al. (1999), Agarwal (2004), Kosowski et al. (2007), Agarwal et al. (2009), Patton (2009) e Jagannathan et al. (2010).

Geralmente, para avaliar como as exposiçōes aos fatores de risco variam ao longo do tempo, alguns pesquisadores implementam RBSA através de OLS (mínimos quadrados) rolling-windows. ${ }^{2}$ Dor e Jagannathan (2003) e Pattarin et al. (2004) sugerem aplicar análise de regressão em vários períodos ao longo do tempo para se avaliar a consistência das exposiçōes. Por outro lado, Brown e Goetzmann (2003), Corielli e Meucci (2004), Swinkels e Sluis (2006), Mamaysky et al. (2008) e Bodson et al. (2010), entre outros, argumentam que a abordagem do filtro de Kalman é a mais adequada para se capturar a dinâmica nas exposições dos hedge funds aos fatores de risco ao longo do tempo.

Bollen e Whaley (2009) buscam identificar alterações na exposições dos hedge funds aos fatores de risco através de metodologia que permite identificar quebras estruturais nos pesos dos fatores. A abordagem empregada trata as exposições aos fatores de risco como constantes entre dois pontos de quebra, com uma mudança abrupta para um novo valor nos pontos de mudança. Os autores identificam mudanças significativas nos parâmetros dos fatores de risco em $40 \%$ da amostra de fundos analisada. Patton e Ramadorai (2011) aplicam o modelo RBSA a uma base de dados diária composta por aproximadamente 15.000 fundos de investimentos de diversos países e ressaltam a importância do uso de informaçōes diárias para modelar as exposiçōes de hedge funds aos fatores de risco. Esses autores também destacam a relevância de se levar em conta as variaçōes ao longo do tempo nas exposiçōes aos fatores de risco.

Mais recentemente, Weng e Trück (2011) aplicam análise de estilo a uma base de dados de fundos asiáticos. Os autores estimam o modelo RBSA no formato original e também analisam a dinâmica na exposição aos fatores de risco através de OLS rolling-windows com o objetivo de analisar variaçöes ao longo do tempo nas exposiçôes aos fatores de risco dos fundos asiáticos. Jawadi e Khanniche (2012) empregam modelos não lineares, como a smooth transition regression (STR), e modelos de Markov switching para capturar as variações nas exposiçōes ao longo do tempo e assimetrias nas relaçōes entre os retornos dos hedge funds e fatores de risco. Outras aplicaçóes recentes da análise de estilo usando dados diários em diferentes amostras de hedge funds são realizadas também por Kugler et al. (2010) e Pojarliev e Levich (2010).

Aplicações de RBSA a dados de fundos multimercados brasileiros podem ser encontradas nos trabalhos de Varga e Valli (1998), Pizzinga e Fernandes (2005), Pizzinga et al. (2006) e Pizzinga et al. (2008). Almeida et al. (2007) propōem o que chamam de análise de estilo robusta e aplicam a dois fundos de investimentos brasileiros, encontrando evidências de mudanças nas alocaçōes ao longo do tem-

2 Ver, por exemplo, Sáez e Izquierdo (2000) e Annaert e Van Campenhout (2002, 2007). 
po. Pizzinga et al. (2011) aplicam a análise de estilo generalizada a fundos cambiais brasileiros no período de 2001 a 2004. Já Marques et al. (2012) aplicam uma versão dinâmica do modelo RBSA a fundos atuariais brasileiros e concluem que tais fundos investem principalmente em títulos indexados à inflação. Nota-se que existem poucos trabalhos envolvendo aplicações da análise de estilo a dados de fundos brasileiros. Uma possível explicaçăo é que a indústria brasileira de fundos vem ganhando relevância, principalmente a partir da segunda metade dos anos 1990, com a estabilidade macroeconômica, consequentemente bases de dados consistentes são relativamente recentes.

Além disso, conforme Sharpe (1992) adverte, a escolha de classes de ativos relevantes é um ponto essencial para o sucesso do modelo, e, principalmente no Brasil, os trabalhos apontam não existir muitos índices referenciais eficazes difundidos no mercado, o que dificulta a aplicação do modelo de Sharpe no país. Varga e Valli (1998), que foram os primeiros autores a introduzir a análise de estilo no país, salientam que isso ocorre principalmente na busca de índices de investimento em renda fixa. Foi apenas mais recentemente que o mercado financeiro brasileiro desenvolveu e difundiu novos índices referenciais, permitindo aplicar a análise de estilo a fundos brasileiros de forma mais confiável.

\section{$3 \mathrm{~A}$ Indústria de Fundos de Investimento no Brasil}

De acordo com Alves Júnior (2003), no Brasil, diferentemente dos Estados Unidos, o surgimento dos fundos de investimento foi fruto direto da política econômica, sendo seu desenvolvimento inicial associado à iniciativa regulatória. $O$ primeiro fundo de investimento fechado, Valéria Primeira, do grupo Deltec, iniciou suas operaçōes em 1952. Já o primeiro fundo aberto, o Fundo Brasil, entrou em atividade pouco depois, em 1954, e, em 1957, foi estabelecido o fundo Crescinco, que tinha como objetivo financiar projetos para o crescimento do país no governo do mineiro Juscelino Kubitschek.

O mercado financeiro brasileiro, até entăo muito incipiente, recebeu um grande impulso e começou a mudar em 1964 com a Lei da Reforma Bancária, através da qual se criaram instituições como o Conselho Monetário Nacional $(C M N)$ e o Banco Central. Nos anos 1970, surgiram novas regras para estruturar o mercado financeiro nacional, destacando-se a legislação sobre fundos mútuos de investimento. Tanto a reforma de 1964, quanto as inúmeras resoluções e decretos que se seguiram visavam a constituição de um sistema financeiro capaz de ampliar a oferta privada de recursos financeiros a longo prazo, apoiado em operaçōes de crédito e no mercado de capitais, visando construir mecanismos alternativos de financiamento de longo prazo que não fossem de origem estatal, substituindo o fi- 
nanciamento pela via dos déficits orçamentários e da expansăo monetária (ALVES JÚNIOR, 2003).

A abertura da economia brasileira nos anos 1990 e a estabilidade monetária alcançada após o Plano Real foram os grandes propulsores da indústria de fundos de investimento nas duas últimas décadas, pois propiciaram novas perspectivas de investimento para os brasileiros. Desde então, a indústria de fundos vem apresentando um crescimento expressivo, tanto no que diz respeito ao valor do patrimônio líquido administrado, quanto em relaçăo à quantidade de fundos oferecidos no mercado, representando hoje um instrumento de poupança importante à disposição de parcela significativa da população. Nas últimas duas décadas, o montante de recursos administrados pelos fundos de investimento no Brasil passou de menos de $R \$ 100$ bilhões, no início dos anos 1990 , para aproximadamente $R \$ 1,88$ trilhão, em abril de 2012, conforme dados da Associação Brasileira das Entidades dos Mercados Financeiro e de Capitais (ANBIMA - ASSOCIAÇĀO BRASILEIRA DAS ENTIDADES DOS MERCADOS FINANCEIRO E DE CAPITAIS, 2012), enquanto o número de fundos passou de aproximadamente 289 para algo em torno de 11.824 nos dias atuais.

Esse expressivo crescimento permitiu o desenvolvimento e a oferta de fundos com estratégias mais específicas, visando atender aos distintos perfis de risco e retorno dos investidores. Foi, portanto, só a partir da métade da década de 1990 que surgiram os primeiros fundos multimercados no Brasil. A Comissão de Valores Mobiliários (CVM), órgão responsável pela regulação e fiscalização dos fundos de investimento no Brasil, define em suas as instruçôes normativas ${ }^{3}$ que os fundos multimercados devem possuir políticas de investimento que envolvam vários fatores de risco, sem o compromisso de concentração em nenhum fator especial ou em fatores diferentes das demais classes de fundos, podendo utilizar derivativos, tanto para alavancagem, quanto para proteção da carteira, gerando possibilidades de perda superior ao patrimônio do fundo. Dessa forma, os fundos multimercados são os que possuem maior liberdade de gestăo, mas também apresentam maior risco, na medida em que seguem diversas estratégias de aplicaçăo de recursos e que não existe nenhum benchmark amplamente aceito ao qual possam ser comparados.

Acompanhando o movimento de toda indústria de fundos, os fundos de investimento multimercados também vêm apresentando um crescimento significativo. Segundo dados da ASSOCIAÇÃO... (2012), em abril de 2012, o volume administrado por esses fundos era de aproximadamente $R \$ 428$ bilhões, o que representa $20,46 \%$ do total da indústria brasileira, composta por 11.824 fundos de investimento, dentro dos quais $5.848(49,46 \%)$ são classificados na categoria multimercados da CVM.

3 A principal instruçăo normativa que regula os fundos de investimento no Brasil é a IN 409 da CVM. 
O crescimento da indústria de fundos aumenta as possibilidades de aplicação para investidores, mas, ao mesmo tempo, torna a decisão de investimento mais complexa, principalmente no caso de fundos multimercados. Nesse contexto, é cada vez maior a necessidade, por parte dos potenciais investidores, de informações detalhadas a respeito dos fundos e de suas estratégias de seleção de carteiras, para que eles possam alocar seus recursos de maneira mais eficiente.

Tendo em vistas essas dificuldades, e com o objetivo de estabelecer principios e normas que fossem além das exigidas pela CVM, a Associação Nacional dos Bancos de Investimento (ANBID) criou, no ano 2000, o Código de Autorregulação dos Fundos de Investimento (ANBID - Associação Nacional dos Bancos de Investimento, 2011), qual deve ser observado por todas as instituições participantes a fim de receberem o selo de qualificação que atesta maior transparência e padronização nos processos dos fundos. Atualmente, praticamente todos os fundos existentes no Brasil adotam as melhores práticas definidas no código de autorregulaçāo da Anbima. ${ }^{4}$ Dentre outras exigências, o código define que os fundos devem obrigatoriamente possuir a classificação Anbima. O modelo de classificação da Anbima visa diminuir a classificação de fundos com políticas distintas dentro de uma mesma classe. Dessa forma, os fundos classificados como multimercados pela CVM são distribuídos em dez classes distintas pela Anbima, descritas no Apêndice B.

\section{Metodologia: Análise de Estilo Baseada nos Retornos}

Embora seja possivel determinar o estilo de investimento de um fundo a partir de uma análise detalhada da carteira mantida, a RBSA é uma abordagem simples que usa apenas os retornos realizados do fundo e dos fatores de risco. $\mathrm{O}$ interesse da análise de estilo, conforme implementada neste artigo, não é efetivamente na carteira mantida pelo fundo de investimento, mas sim nas exposiçôes dos fundos a certos fatores de risco.

\subsection{O Modelo}

Suponha-se que existam $K$ fatores imitando portfólios, com vetor de retornos $f_{t}$, que determinam os retornos dos ativos. Além disso, existem $N$ fundos multimercados com vetor de retornos $y_{\mathfrak{i t}}$, para os quais tem-se o modelo de fatores linear

$$
y_{\mathrm{it}}=\alpha+\beta_{\mathrm{It}} f_{\mathrm{It}}+\ldots+\beta_{\mathrm{kt}} f_{\mathrm{kt}}+\varepsilon_{\mathrm{it}}
$$

\footnotetext{
4 Por decisăo soberana de seus associados, em assembleia realizada no dia 21 de outubro de 2009 , a Anbid integrou suas atividades às da Associação Nacional das Instituiģóes do Mercado Financeiro (Andima), passando ambas a constituir uma só, a Anbima.
} 
no qual: $\varepsilon_{i j}: N\left(0, \Sigma_{i}\right)$ é o $i_{t h}$ vetor de erros de medidas e $\beta_{i t}=\left(\beta_{t t}, \ldots, \beta_{k t}\right)$ é a $i_{t h}$ linha da matriz de pesos dos fatores $\beta_{t}, N \times K$. Assume-se que os termos de erros são não correlacionados, $E\left[\varepsilon_{i t} \varepsilon_{j t}\right]=0 \forall i \in\{1, \ldots, K\} \forall j \in\{1, \ldots, N\}$. Geralmente, entretanto, são impostas duas restrições. A primeira é a restrição de portfólio, a qual requer que as estimativas para os parâmetros $\beta_{i}$ possam ser interpretados como os pesos mantidos pelo portfólio no $i_{\text {th }}$ fator de risco. A restrição fica assim:

$$
\sum_{i=1}^{K} \beta_{i}=1
$$

As equações 1 e 2 juntas são chamadas RBSA semiforte. A segunda restrição refere-se à restrição de venda a descoberto, a qual impõe que todos os pesos estimados do portfólio devem ser positivos (apenas posiçōes compradas):

$$
\beta_{i}=1 \geq 0, \quad i=1, \ldots, K .
$$

Isso não significa que vendas a descoberto em geral são proibidas, mas sim que não são permitidas vendas a descoberto em categorias de estilo. A versão forte da RBSA é obtida pela equação 1 junto com as restrições 2 e 3 .

A imposição de que as sensibilidades a todas as classes de ativos somem $100 \%$ é um aspecto metodológico importante do modelo proposto por Sharpe (1992). Com isso, os coeficientes podem ser vistos como os percentuais de alocação da carteira, tornando a sua interpretação mais intuitiva. No entanto, como Brown e Goetzmann (1997) ressaltam, os parâmetros representam na verdade as sensibilidades do retorno do fundo às classes de ativos, e não efetivamente os percentuais da composiçāo da carteira do fundo, apesar de ser possivel pensar neles como proxies desses percentuais.

Uma das hipóteses implícitas do modelo RBSA original é que as exposições são mantidas constantes ao longo do tempo, o que é altamente improvável na prática. Sharpe (1992) ressalta que o resultado obtido na análise de estilo é a média do estilo do período analisado, pois o fundo tem alta probabilidade de sofrer mudanças de estilo ao longo do tempo. Dessa forma, o autor sugere que examinar o comportamento do fundo ao longo do tempo pode ser útil e que, para isso, basta estimar uma série de análises de estilos usando um número de meses fixos em cada estimação. No entanto, o uso de subamostras, ao invés da amostra inteira, significa a introdução implícita de exposições variando ao longo do tempo de maneira ad hoc. Tal abordagem assume que as exposições se mantém constantes ao longo do período de estimaçāo definido (janela). Em casos de mudança na gestāo de um fundo, por exemplo, assumir que as exposiçōes são constantes ao longo de um periodo pode ser bastante restritivo. 
$\mathrm{Na}$ interpretação do resultado do modelo, Sharpe atribui ao $R^{2}$ estimado a parcela do retorno do fundo que é explicada pelo estilo, e a diferença $\left(1-R^{2}\right)$ refere-se à parcela do retorno do fundo explicada pela seleção individual de ativos. Em outras palavras, define-se que um baixo $R^{2}$ representa uma gestão mais ativa e um elevado $R^{2}$ a uma gestão mais passiva: "In a sense, a passive fund manager provide an investor with an investment style, while an active manager provides both style and selection" (SHARPE, 1992, p. 12). Sharpe reforça, contudo, que a interpretação do $R^{2}$ depende de que modelo inclua as classes de ativos mais relevantes, caso contrário, um baixo $R^{2}$ pode ser devido também à má especificação do modelo, $\mathrm{e}$ não apenas a uma gestão ativa de seleção de ativos.

A abordagem proposta neste artigo consiste em estimar a dinâmica das exposições dos fundos ao longo do tempo através da estimação do modelo com parâmetros variando no tempo. Dessa forma, o período amostral inteiro é usado para estimar a exposição em cada ponto do tempo, consequentemente, não é necessário escolher o tamanho da janela. A estimação através filtro de Kalman define os pesos ótimos de cada observação na determinação das exposições.

\subsection{Estimação do Modelo no Formato Estado Espaço através de Filtro de Kalman}

Nota-se que a equação 1 pode ser escrita de forma geral como:

$$
\mathrm{y}_{\mathrm{it}}=f_{t} \beta_{t}+\varepsilon_{\mathrm{t}}
$$

em que $f_{t}=\left[1, f_{1}, \ldots, f_{k]}\right]$ são as variáveis explicativas (fatores de risco) usadas no período de tempo te $\beta \mathrm{t}=\left[\alpha_{\mathrm{t}^{\prime}} \beta_{\mathrm{It} t^{\prime}}, \ldots, \beta_{\mathrm{kt}}\right]$ são os pesos dos fatores variantes no tempo.

Supondo-se que o vetor de parâmetros, na equação 1, segue um passeio aleatório, tem-se:

$$
\beta_{t}=\beta_{t-1}+\varepsilon_{t}
$$

em que $\varepsilon_{i}: N\left(0, \Sigma_{\varepsilon}\right)$.

Com isso, as equações 1 e 5 formam um modelo de estado-espaço e seus parâmetros podem ser estimados por máxima verossimilhança. A função de verossimilhança de modelos de estado-espaço pode ser construída através do filtro de Kalman, e estimativas dos parâmetros variantes no tempo também podem ser obtidas. ${ }^{5}$ Mais especificamente, dada a esperança condicional dos parâmetros variantes no tempo, as observaçóes, denotadas por $\beta_{t \mid t-1}$, e a matriz de erro quadrático médio dessa esperança, denotada por $P_{t \mid t-1}$. Então, para dados valores de $\beta_{t \mid t-1}$ e $P_{t i t-1}$, quando uma nova observação $y_{i t}$ fica disponível, o erro de previsão pode

5 Ver, por exemplo, Durbin e Koopman (2001) e Kim e Nelson (1999).

SCHUTT, I, G.; CALDEIRA, J. F. Análise de Estilo Dinâmica de Fundos Multimercados... 
ser calculado como $v_{t}=y_{i t}-f_{t} \beta_{t \mid-1}$. Logo, após observar $y_{i t}$, uma inferência mais acurada a respeito dos estados (parâmetros variantes no tempo) pode ser feita:

$$
\begin{gathered}
\beta_{t \mid t}=\beta_{t \mid t-1} P_{t \mid t} f_{t} v_{t} \\
P_{t \mid t}=P_{t \mid t-1}-P_{t \mid k-1} f_{t} \Delta_{t}^{-1} f_{t} P_{t \mid t-1},
\end{gathered}
$$

em que $\Delta_{t}=f_{t} P_{t \mid t-1} f_{t}+\sigma^{2}$ é a matriz de covariância do erro de previsão $\mathrm{v}_{t}$. A previsão $\beta_{\mathrm{t}+1 \mid \mathrm{t}}$ pode agora ser realizada usando $\beta_{\mathrm{t} \mid \mathrm{t}}$ e a equação 5:

$$
\begin{gathered}
\beta_{t+1 \mid t}=\beta_{t \mid t} \\
P_{t+1 \mid t}=P_{t \mid}+\Sigma_{\varepsilon}
\end{gathered}
$$

Esses cálculos podem ser realizados recursivamente para $t=1, \ldots, T$. Por causa da natureza não estacionária da equação de transição dos estados (equação 5), o filtro de Kalman foi iniciado usando a formulação exata proposta por Koopman (1997). Os parâmetros desconhecidos na matriz de covariância $\Sigma_{\varepsilon}$ são coletados no vetor de parâmetros $\psi$, juntamente com $\sigma^{2}$ e qualquer outro parâmetro fixo no tempo. A estimação de $\psi$ é obtida através da maximização numérica do log da função de verossimilhança, a qual é construída através da decomposição do erro de previsão e é dada por:

$$
l(\psi)=-\frac{T}{2} \log (2 \pi)-\frac{1}{2} \sum_{t=1}^{T} \log \left|\Delta_{t}\right|-\frac{1}{2} \sum_{t=1}^{T} v_{t} \Delta_{t}^{-1} v_{t}
$$

\section{Dados e Resultados Empíricos}

Esta seção apresenta os resultados empíricos da análise de estilo realizada usando fundos multimercados brasileiros. Inicialmente, foram identificados os fatores de risco apropriados a ser usados na análise de estilo. Na segunda etapa, o modelo de análise de estilo é implementada relaxando as hipóteses das equações 2 e 3 do modelo original proposto por Sharpe (1992).

\subsection{S Dados}

A base de dados utilizada é composta por 388 fundos multimercados, e como variáveis explicativas são considerados sete fatores de risco relevantes para o mercado brasileiro. O período amostral vai de janeiro de 2006 a outubro de 2011 , perfazendo um total de 1.493 observações diárias. As séries de retornos dos fundos foram 
obtidas através da consulta e extração das cotas diárias do sistema Economática. ${ }^{6} \mathrm{O}$ critério de seleção dos fundos foi:

a) ser classificado na CVM como multimercados;

b) ter data do início da série de cotas anterior a 31 de dezembro de 2005;

c) estar ativo em 31 de outubro de 2011 ;

d) apresentar patrimônio líquido superior a $\mathbf{R} \$ 30$ milhōes em 31 de outubro de 2011.

Do universo de 11.377 fundos de investimentos cadastrados na Anbima, em outubro de 2011, em torno de 6.185 estâo classificados em categorias que permitem exposição a diversos fatores de risco, correspondendo, portanto, aos fundos multimercados conforme a classificação da CVM.7 Após a aplicação dos filtros descritos, restaram em torno de 550 fundos na base de dados da Economática. Para o cálculo da rentabilidade diária, no entanto, só foram utilizados os dados de 388 fundos devido à ausência de informação na série histórica de cotas para alguns dias úteis em diversos fundos e a retirada de quatro outliers.

Apesar de serem da mesma classificação CVM, os fundos selecionados podem apresentar características bastante distintas entre si. A Tabela 1 apresenta estatisticas referentes à classificação Anbima dos fundos classificados em categorias que permitem exposição a diversos fatores de risco, sendo classificados como multimercados. Uma descrição mais detalhada de cada categoria é apresentada no apêndice A. A Tabela 2 mostra alguns dados referentes às principais características dos fundos que compóem a amostra analisada, pela classificação Anbima, tais como: a cobrança de taxa de performance e o tipo de fundo - exclusivo ou năo, se permite alavancagem, aplicaçăo em títulos de crédito privado, ou em ativos no exterior. Mais detalhes săo apresentados no apêndice $\mathrm{A}$.

6 Economatica ê uma ferramenta para análise de açōes e de fundos de investimento. Trata-se de um conjunto de avançados módulos de análise que operam sobre uma base de dados de grande abrangência e de alta confiabilidade. Mais informaçōes em: http:/www.economatica.com/pt.

7 Nessa base estão incluídos também os fundos classificados na Anbima como fundos de previdência com exposição a diversos fatores de risco.

SCHUTT, I, G.; CALDEIRA, J. F. Análise de Estilo Dinâmica de Fundos Multimercados... 
Tabela 1 - Classificação dos fundos pela Anbima

\begin{tabular}{|c|c|c|c|c|c|c|c|c|}
\hline \multirow{3}{*}{ FUNDOS } & \multicolumn{4}{|c|}{ UNIVERSO DA ANBIMA } & \multicolumn{4}{|c|}{ UNIVERSO DO ESTUDO } \\
\hline & \multicolumn{2}{|c|}{ № de Fundos } & \multicolumn{2}{|c|}{\begin{tabular}{|l} 
Patrimônio Líquido \\
\end{tabular}} & \multicolumn{2}{|c|}{ № de Fundos } & \multicolumn{2}{|c|}{ Patrimônio Líquido } \\
\hline & QTD & $\%$ & RS milhões & $\%$ & QTD & $\%$ & RȘ milhões & $\%$ \\
\hline Balanceados & 49 & $1 \%$ & 2.702 & $1 \%$ & 12 & $3 \%$ & 2.289 & $2 \%$ \\
\hline Capital protegido & 81 & $1 \%$ & 5.677 & $1 \%$ & - & $0 \%$ & - & $0 \%$ \\
\hline Long and short - Neutro & 83 & $1 \%$ & 3.874 & $1 \%$ & 8 & $2 \%$ & 961 & $1 \%$ \\
\hline Long and short - Direcional & 97 & $2 \%$ & 5.914 & $1 \%$ & 4 & $1 \%$ & 1.044 & $1 \%$ \\
\hline Multimercados macro & 388 & $6 \%$ & 48.006 & $12 \%$ & 39 & $10 \%$ & 5.338 & $4 \%$ \\
\hline Multimercados trading & 27 & $0,44 \%$ & 1.611 & $0 \%$ & - & $0 \%$ & - & $0 \%$ \\
\hline Multim multiestratégia & 3.002 & $49 \%$ & 216.974 & $53 \%$ & 153 & $39 \%$ & 58.026 & $47 \%$ \\
\hline Multimercados multigestor & 1.579 & $26 \%$ & 12.646 & $3 \%$ & 54 & $14 \%$ & 5.712 & $5 \%$ \\
\hline Multimercado juros e moedas & 267 & $4 \%$ & 91.678 & $23 \%$ & 63 & $16 \%$ & 34.482 & $28 \%$ \\
\hline Multimercado estratégia específica & 154 & $2 \%$ & 7.731 & $2 \%$ & 13 & $3 \%$ & 5.111 & $4 \%$ \\
\hline Previdenciários balanceados até 15 & 41 & $1 \%$ & 2.592 & $1 \%$ & 10 & $3 \%$ & 667 & $1 \%$ \\
\hline Previdenciários balanceados de 15 a 30 & 69 & $1 \%$ & 1.832 & $0 \%$ & 19 & $5 \%$ & 3.735 & $3 \%$ \\
\hline Previdenciários balanceados acima de 30 & 98 & $2 \%$ & 2.447 & $1 \%$ & 12 & $3 \%$ & 2.266 & $2 \%$ \\
\hline Previdenciários data-alvo & 35 & $1 \%$ & - & $0 \%$ & - & $0 \%$ & - & $0 \%$ \\
\hline Previdenciários multimercados & 215 & $3 \%$ & 2.594 & $1 \%$ & 5 & $1 \%$ & 1.179 & $1 \%$ \\
\hline TOTAL & 6.185 & $0 \%$ & 406.277 & $0 \%$ & 392 & $0 \%$ & 120.810 & $0 \%$ \\
\hline
\end{tabular}

Fonte: Elaboração própria.

Tabela 2 - Características dos fundos do estudo

\begin{tabular}{|c|c|c|c|c|c|}
\hline Classificação Anbima & Cobra Performance & Exclusivo & Alavancado & Crédito Privado & Investimento no Exterior \\
\hline Balanceados & 0 & 7 & 0 & 0 & 4 \\
\hline Long and short - Direcional & 4 & 0 & 4 & 0 & 3 \\
\hline Long and short - Neutro & 7 & 1 & 8 & 0 & 5 \\
\hline Multimercado estratégia específica & 4 & 5 & 4 & 5 & 3 \\
\hline Multimercado juros e moedas & 19 & 41 & 10 & 12 & 17 \\
\hline Multimercados macro & 10 & 19 & 19 & 3 & 18 \\
\hline Multimercado multiestratégia & 53 & 96 & 91 & 40 & 83 \\
\hline Multimercado multigestor & 3 & 43 & 47 & 19 & 35 \\
\hline Previdência açöes & 0 & 0 & 0 & 0 & 1 \\
\hline Previdenciários balanceados de 15 a 30 & 0 & 16 & 0 & 1 & 1 \\
\hline Previdenciários balanceados acima de 30 & 0 & 11 & 0 & 1 & 0 \\
\hline Previdenciários balanceados até 15 & 0 & 9 & 0 & 0 & 0 \\
\hline Previdenciários multimercados & 0 & 5 & 0 & 5 & 0 \\
\hline TOTAL & 100 & 253 & 183 & 86 & 170 \\
\hline$\%$ do total do estudo & $25,45 \%$ & $64,38 \%$ & $46,56 \%$ & $21,88 \%$ & $43,26 \%$ \\
\hline
\end{tabular}

Fonte: Elaboração própria.

\section{2 Índices de Mercado: Fatores de Risco}

Em relação aos fatores de risco considerados, em um primeiro momento buscou-se identificar os principais riscos aos quais as classes de ativos do mercado brasileiro estão expostas, sendo eles, resumidamente: curva de juros prefixada; mercado de ações; curva de cupom de inflação; e mercado de câmbio, além do fator livre de risco. Num segundo momento, buscou-se identificar no mercado brasileiro os índices mais aceitos e difundidos que pudessem representar as classes de ativos expostas a esses riscos. Dessa forma, são apresentados, a seguir, os índices mais representativos dos investimentos no Brasil: ${ }^{8}$

8 Uma descrição mais detalhada dos fatores de risco considerados neste estudo é apresentada no Apêndice B. 
a) IRF-MI e IRF-M1+: para risco da curva de juros prefixada;

b) Ibovespa: para risco do mercado de açōes;

c) IMA-B5 e IMA-B5+: para risco de inflação;

d) Dólar - PTAX: para risco de taxa de câmbio;

e) CDI: para fator livre de risco.

A Tabela 3 apresenta estatísticas descritivas dos fundos multimercados e retornos dos fatores de estilo. São apresentados a média dos retornos, mediana, desvio padrão, mínimo e máximo, assimetria e curtose para os fundos multimercados e fatores de estilo selecionados durante o período de janeiro de 2006 a outubro de 2011.

Tabela 3 - Estatísticas descritivas

\begin{tabular}{lcccccccccc}
\hline & Fundos de Investimento & IRF-M 1 & IRF-M 1+ & IRF-M & IMA-B 5 & IMA-B 5+ & IMA-B & CDI & IBOV & PTAX \\
\hline Média & $\mathbf{0 , 0 4 3}$ & 0,047 & 0,055 & 0,051 & 0,057 & 0,070 & 0,061 & 0,044 & 0,058 & $(0,017)$ \\
Mediana & $\mathbf{0 , 0 4 4}$ & 0,046 & 0,062 & 0,057 & 0,056 & 0,066 & 0,063 & 0,044 & 0,106 & $(0,056)$ \\
Máximo & $\mathbf{9 , 7 8 4}$ & 0,327 & 1,381 & 0,882 & 1,376 & 3,242 & 1,904 & 0,066 & 14,659 & 9,327 \\
Minimo & $\mathbf{6}, 862$ & $(0,255)$ & $(2,677)$ & $(1,708)$ & $(1,326)$ & $(4,698)$ & $(2,671)$ & 0,032 & $(11,393)$ & $(8,803)$ \\
Desvio padrão & $\mathbf{0 , 3 2 8}$ & 0,029 & 0,242 & 0,142 & 0,172 & 0,493 & 0,290 & 0,008 & 2,023 & 1,052 \\
Curtose & $\mathbf{5 9 , 4 3}$ & 24,875 & 20,300 & 25,487 & 13,262 & 15,404 & 13,246 & 0,131 & 6,299 & 13,483 \\
Assimetria & $\mathbf{0 , 3 3 4}$ & $(0,534)$ & $(1,334)$ & $(1,522)$ & $(0,474)$ & $(0,503)$ & $(0,751)$ & 0,491 & 0,194 & 0,810 \\
\hline \multicolumn{8}{c}{ Fonte: Elaboração própria. }
\end{tabular}

O retorno diário médio dos fundos multimercados é $0.043 \%$, com desvio padrão de $0.328 \%$. Os fatores de risco, em geral, apresentam retorno médio positivo, assimetria negativa e elevada curtose.

\subsection{Resultados Empíricos da Análise de Estilo}

O modelo fatorial adotado neste estudo busca capturar a exposição e medir a sensibilidade dos fundos de investimento multimercados aos principais fatores de risco advindos dos mercados de renda fixa, variável e cambial. Desse modo, o modelo inclui quatro variáveis que atuam como proxies dos fatores relativos ao mercado de renda fixa (IRF-M1, IRFM1 +, IMAB5, IMAB5 + e CDI), um fator relativo ao mercado de renda variável (lbovespa) e um fator relativo ao mercado cambial (PTAX):

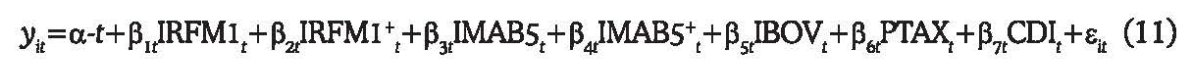

Analisando as críticas e contribuições já realizadas ao trabalho original de Sharpe (1992), principalmente no que diz respeito à aplicação da análise de estilo para o mercado de hedge funds, e considerando que grande parte dos fundos multimercados pode operar alavancada e com posiçōes vendidas, as restriçōes das equaçōes 2 e 3 são abandonadas neste estudo. Em outras palavras, será realizada uma análise de estilo fraca, conforme nomenclatura definida em Horst et al. (2004). Relaxando as restrições de desigualdade, os coeficientes podem ser obtidos através do método de mínimos quadrados (OLS). 
Inicialmente, o modelo RBSA é estimado conforme proposto por Sharpe (1992), em que os parâmetros relativos às exposições são estimados usando toda a amostra. Posteriormente, levando-se em conta a possibilidade de mudança de estilo ao longo do tempo, e a própria sugestão de Sharpe, a amostra é dividida em quatro períodos com 366 observações cada, e o modelo é estimado para cada período separadamente.

A Tabela 4 mostra os resultados para a análise de estilo dos fundos multimercados brasileiros de janeiro de 2006 a outubro de 2011. A primeira linha traz os pesos para todos os fatores de estilo. O coeficiente de determinação ajustado, $R^{2}$ é reportado na primeira coluna.

Tabela 4 - Análise de estilo generalizada dos fundos multimercados (OLS)

\begin{tabular}{|c|c|c|c|c|c|c|c|c|c|}
\hline \multicolumn{10}{|c|}{ Estatísticas dos Betas - Período todo } \\
\hline & $\mathbf{R}^{\mathbf{\Lambda} 2}$ & $\boldsymbol{\alpha}$ & IRF-M1 & IRF-M1+ & IMA-B5 & IMA-B5+ & IBOV & CDI & PTAX \\
\hline Média & 0,4686 & $-0,0041$ & 0,1430 & $-0,0150$ & 0,1140 & 0,0270 & 0,6700 & $-0,0220$ & 0,0440 \\
\hline Mediana & 0,5044 & $-0,0016$ & 0,0600 & $-0,0040$ & 0,0740 & 0,0150 & 0,7970 & $-0,0090$ & 0,0070 \\
\hline Desvio padrão & 0,2684 & 0,0305 & 0,4770 & 0,1230 & 0,1850 & 0,0420 & 0,6720 & 0,0430 & 0,0810 \\
\hline Curtose & 1,788 & 10,328 & 8,501 & 7,847 & 11,515 & 12,569 & 6,499 & 24,567 & 22,641 \\
\hline Assimetria & $-0,215$ & $-0,559$ & 0,423 & $-0,268$ & $-0,519$ & 1,753 & $-0,562$ & 0,525 & 3,275 \\
\hline \multicolumn{10}{|c|}{ Intervalo Interquintil Betas - Período todo } \\
\hline Quintil & $\mathbf{R}^{\wedge} \mathbf{2}$ & $\alpha$ & IRF-M1 & IRF-M1+ & IMA-B5 & IMA-B5+ & IBOV & CDI & PTAX \\
\hline 0.20 & 0,1700 & $-0,0188$ & $-0,0870$ & $-0,0700$ & 0,0110 & 0,0010 & 0,2730 & $-0,0390$ & 0,0000 \\
\hline 0.40 & 0,3980 & $-0,0045$ & 0,0120 & $-0,0230$ & 0,0550 & 0,0100 & 0,6260 & $-0,0180$ & 0,0010 \\
\hline 0.60 & 0,5540 & 0,0007 & 0,1200 & 0,0050 & 0,1070 & 0,0250 & 0,8990 & $-0,0030$ & 0,0160 \\
\hline 0.80 & 0,717 & 0,008 & 0,367 & 0,039 & 0,234 & 0,047 & 1,051 & 0,000 & 0,095 \\
\hline
\end{tabular}

Fonte: Elaboração própria.

A Tabela 4 apresenta os resultados para o modelo estimado com a amostra completa. A primeira coluna da tabela traz o $R^{2}$ médio, a primeira linha das demais colunas mostra as exposições médias do conjunto de fundos analisados a cada um dos fatores de risco. No restante da tabela, são apresentadas outras estatísticas que ajudam na análise das exposições dos fundos a cada fator de risco. Nota-se que $\circ R^{2}$ médio para o conjunto de fundos ficou próximo de 0.50 . Considerando a interpretação proposta por Sharpe (1992), o $R^{2}$ refere-se à parte do retorno do fundo que é explicada pelo estilo, e a diferença $\left(1-R^{2}\right)$ é parcela do retorno do fundo explicada pela seleção individual de ativos. Comparando resultados encontrados em outros trabalhos (por exemplo, de Weng e Trück (2011)), o $R^{2}$ encontrado aqui é relativamente alto, indicando uma gestão mais passiva por parte dos gestores de fundos multimercados brasileiros. Assim, a análise de estilo pode explicar $50 \%$ da variância dos fundos multimercados e a parcela da variância inexplicada pode ser atribuída à habilidade dos gestores.

Na segunda parte da Tabela 4 é analisado o resultado por quintil das exposições. ${ }^{9}$ Nota-se que, no quintil mais alto, os fundos exibem $R^{2}$ superior a 0.71 . Em relação ao estilo dos fundos, pode-se afirmar que o lbovespa, o IRF-M1 e o IMA-B5

9 Os parâmetros referentes ao modelo estimado para cada fundo individualmente năo foram apresentados para poupar espaço, mas podem ser fornecidos pelos autores mediante solicitaçăo. 
são os fatores de risco mais relevantes para explicar o retorno da indústria como um todo. Em particular, os fundos multimercados exibem elevada exposição à renda variável, representada aqui pelo Ibovespa, com média de $67 \%$. A exposição líquida ao mercado de títulos de renda fixa ${ }^{10}$ é de aproximadamente $22 \%$, indicando que os fundos multimercados mantêm uma parcela significante de seus recursos em ativos relacionados a títulos públicos ou títulos de renda fixa privados.

Considerando que dificilmente os fundos multimercados mantêm fixas as exposições aos fatores de risco, e com o intuito de verificar como o estilo dos fundos varia no período analisado, a amostra foi dividida em quatro subperíodos e o modelo foi estimado para as quatro subamostras separadamente. A Tabela 5 traz as exposiçōes médias dos fundos aos fatores de risco por período, bem como um resumo das estatísticas referentes aos modelos estimados. Fica evidente que os parâmetros estimados são bastante distintos entre os períodos, indicando que a exposição dos fundos aos fatores de risco variam ao longo do tempo.

Tabela 5 - Exposições dos fundos aos fatores de risco por período

\begin{tabular}{|c|c|c|c|c|c|c|c|c|c|c|}
\hline & & $\mathrm{R}^{\wedge} \mathbf{2}$ & $\alpha$ & IRF-M1 & IRF-M1+ & IMA-B5 & IMA-B5+ & IBOV & $\mathrm{CDI}$ & PTAX \\
\hline \multirow{5}{*}{ Período 1} & Média & 0,485 & $-0,008$ & $-0,279$ & 0,057 & 0,106 & 0,016 & 0,772 & $-0,053$ & 0,020 \\
\hline & Mediana & 0,554 & $-0,005$ & $-0,151$ & 0,033 & 0,070 & 0,010 & 0,854 & $-0,020$ & 0,002 \\
\hline & Desvio padrão & 0,241 & 0,094 & 0,819 & 0,234 & 0,150 & 0,027 & 0,880 & 0,108 & 0,050 \\
\hline & Curtose & 2,272 & 21,730 & 4,117 & 8,628 & 10,876 & 16,072 & 4,517 & 17,095 & 14,619 \\
\hline & Assimetria & $-0,303$ & 1,232 & $-0,049$ & 0,533 & 1,815 & 2,149 & $-0,775$ & 1,119 & 2,127 \\
\hline \multirow{5}{*}{ Período 2} & Média & 0,572 & 0,004 & 0,094 & $-0,037$ & 0,203 & 0,020 & 0,445 & $-0,029$ & 0,043 \\
\hline & Mediana & 0,684 & $-0,001$ & 0,041 & $-0,017$ & 0,058 & 0,014 & 0,350 & $-0,009$ & 0,007 \\
\hline & Desvio padrão & 0,281 & 0,156 & 0,672 & 0,173 & 0,395 & 0,123 & 0,933 & 0,054 & 0,079 \\
\hline & Curtose & 1,895 & 14,640 & 5,271 & 5,772 & 9,534 & 20,370 & 3,729 & 16,940 & 24,569 \\
\hline & Assimetria & $-0,532$ & 0,994 & $-0,036$ & $-0,210$ & 2,367 & $-1,995$ & $-0,383$ & $-0,869$ & 3,097 \\
\hline \multirow{5}{*}{ Período 3} & Média & 0,537 & $-0,003$ & 0,145 & $-0,010$ & 0,093 & 0,014 & 0,606 & $-0,006$ & 0,051 \\
\hline & Mediana & 0,528 & $-0,002$ & 0,069 & 0,000 & 0,056 & 0,000 & 0,737 & $-0,001$ & 0,004 \\
\hline & Desvio padrão & 0,330 & 0,042 & 0,427 & 0,120 & 0,172 & 0,059 & 0,771 & 0,027 & 0,099 \\
\hline & Curtose & 1,504 & 13,501 & 12,260 & 44,488 & 15,628 & 16,071 & 5,299 & 61,731 & 20,460 \\
\hline & Assimetria & $-0,061$ & 0,733 & 1,366 & 1,695 & 0,442 & 2,964 & $-1,026$ & 2,775 & 3,259 \\
\hline \multirow{5}{*}{ Período 4} & Média & 0,546 & 0,020 & 0,216 & $-0,018$ & 0,127 & 0,028 & 0,292 & $-0,004$ & 0,057 \\
\hline & Mediana & 0,593 & 0,006 & 0,099 & 0,001 & 0,049 & 0,004 & 0,513 & $-0,001$ & 0,005 \\
\hline & Desvio padrão & 0,309 & 0,096 & 0,445 & 0,148 & 0,275 & 0,074 & 0,931 & 0,018 & 0,102 \\
\hline & Curtose & 1,609 & 25,303 & 7,457 & 20,134 & 26,116 & 16,990 & 3,358 & 28,036 & 15,425 \\
\hline & Assimetria & $-0,248$ & 2,116 & 1,544 & $-3,184$ & 3,642 & 3,320 & $-0,867$ & $-0,453$ & 2,849 \\
\hline
\end{tabular}

Fonte: Elaboração própria.

Nota-se que os fatores de risco com maior peso são os mesmos que apresentam maior oscilação nas exposições entre os períodos analisados: Ibovespa, o IRF-MI e o IMA-B5. Por exemplo, a exposição ao mercado de ações caiu de $77 \%$, no primeiro período, para no último, ficando evidente a diminuição da exposição dos fundos multimercados ao mercado de ações. Por outro lado, o peso da exposição aos fatores relacionados ao mercado de renda fixa exibe crescimento. As exposiçōes aos demais fatores se mantiveram relativamente mais estáveis.

Conforme destacado anteriormente, um ponto fraco da RBSA é a hipótese de que o estilo de investimento de um fundo se mantém fixo ao longo do período amos-

10 Além de títulos de renda fixa públicos e privados, esse fator de risco pode capturar também exposição a derivativos de renda fixa.

SCHUTT, I. G.; CALDEIRA, J.F. Análise de Estilo Dinâmica de Fundos Multimercados... 
tral. ${ }^{11}$ Nota-se na Tabela 5 que, para o conjunto de fundos multimercados considerados, a exposição aos fatores de risco não se mantém a mesma ao longo do tempo. Nesse sentido, com o objetivo de tratar as exposições aos fatores de risco explicitamente como variantes no tempo, o modelo é colocado em formato estado-espaço e é estimado através do filtro de Kalman. Uma das principais vantagens da estimação através do filtro de Kalman é o uso mais eficiente das informaçōes, permitindo que as exposiçōes variem ao longo do tempo sem que seja necessário definir uma janela de estimação. Além disso, com a estimação através do filtro de Kalman toda a amostra é usada para estimar as exposiçóes em cada período, sendo determinado o peso ótimo de cada observação na mensuração da exposição.

A Tabela 6 resume os resultados obtidos com a estimação do modelo de análise de estilo através do filtro de Kalman..$^{12}$ Nota-se que os pesos das exposições são bem parecidos com aqueles obtidos na estimação por OLS, o que era esperado, sendo que a maior diferença é observada no peso do fator Ibovespa. A tabela apresenta estatísticas descritivas para o conjunto de dados composto por 388 fundos de investimentos classificados na CVM como multimercados. Também são apresentadas estatísticas descritivas dos fatores de risco considerados neste estudo.

Tabela 6 - Análise de estilo generalizada dos fundos multimercados (filtro de Kalman)

\begin{tabular}{|c|c|c|c|c|c|c|c|c|c|}
\hline & $R^{\wedge 2}$ & $\alpha$ & IRF-M1 & IRF-M1+ & IMA-B5 & IMA-B5+ & IBOV & CDI & PTAX \\
\hline Média & 0,459 & $-0,001$ & 0,165 & $-0,009$ & 0,090 & 0,002 & 0,589 & 0,053 & $-0,021$ \\
\hline Mediana & 0,458 & $-0,001$ & 0,118 & 0,052 & 0,065 & $-0,001$ & 0,746 & 0,013 & $-0,012$ \\
\hline Desvio padrão & 0,279 & 0,028 & 0,621 & 0,830 & 0,308 & 0,116 & 0,905 & 0,088 & 0,037 \\
\hline Mínimo & 0,030 & $-0,135$ & $-3,461$ & $-4,667$ & $-1,397$ & $-0,484$ & $-5,558$ & $-0,054$ & $-0,174$ \\
\hline Máximo & 0,969 & 0,186 & 2,058 & 3,306 & 1,712 & 0,517 & 5,186 & 0,833 & 0,326 \\
\hline Curtose & 6,821 & 13,161 & 11,363 & 10,986 & 9,106 & 7,951 & 15,746 & 22,576 & 27,285 \\
\hline Assimetria & 0,742 & 1,064 & $-1,347$ & $-0,949$ & 0,112 & $-0,481$ & $-1,569$ & 3,274 & 1,333 \\
\hline \multicolumn{10}{|c|}{ Intervalo Interquintil Betas - Período todo } \\
\hline Quintil & $R^{\wedge} \mathbf{2}$ & $\alpha$ & IRF-M1 & IRF-M1+ & IMA-B5 & IMA-B5+ & IBOV & CDI & PTAX \\
\hline 0.20 & 0,170 & $-0,019$ & $-0,087$ & $-0,070$ & 0,011 & 0,001 & 0,273 & $-0,039$ & 0,000 \\
\hline 0.40 & 0,398 & $-0,005$ & 0,012 & $-0,023$ & 0,055 & 0,010 & 0,626 & $-0,018$ & 0,001 \\
\hline 0.60 & 0,554 & 0,001 & 0,120 & 0,005 & 0,107 & 0,025 & 0,899 & $-0,003$ & 0,016 \\
\hline 0.80 & 0,717 & 0,008 & 0,367 & 0,039 & 0,234 & 0,047 & 1,051 & 0,000 & 0,095 \\
\hline
\end{tabular}

Fonte: Elaboração própria.

Na Figura 1 são mostradas as exposições médias dos fundos estimadas através da abordagem do filtro de Kalman. Período considerado: janeiro de 2010 a outubro de 2011. Uma primeira observação sugere que as exposições variam substancialmente ao longo do tempo. Fica evidente um aumento na exposiçăo ao fator livre de risco e redução na exposição ao mercado de açōes. O ponto de mudança no estilo de investimento ocorre em meados de 2008, coincidindo com a crise financeira deflagrada no período. Cabe destacar que nessa abordagem as exposições em cada ponto do

I1 Ver, por exemplo, Laurens (2006), Mamaysky (2008), Bollen (2009), Patton (2011) e Fredj (2012).

12 Mais uma vez os resultados das estimaçōes individuais para cada fundo são omitidos para poupar espaço, mas podem ser fornecidos mediante solicitaçăo. 
tempo são estimadas usando a amostra inteira, o que permite usar informações dos retornos posteriores ao período para estimar sua exposição naquele ponto do tempo.

Figura 1 - Exposição aos fatores de risco
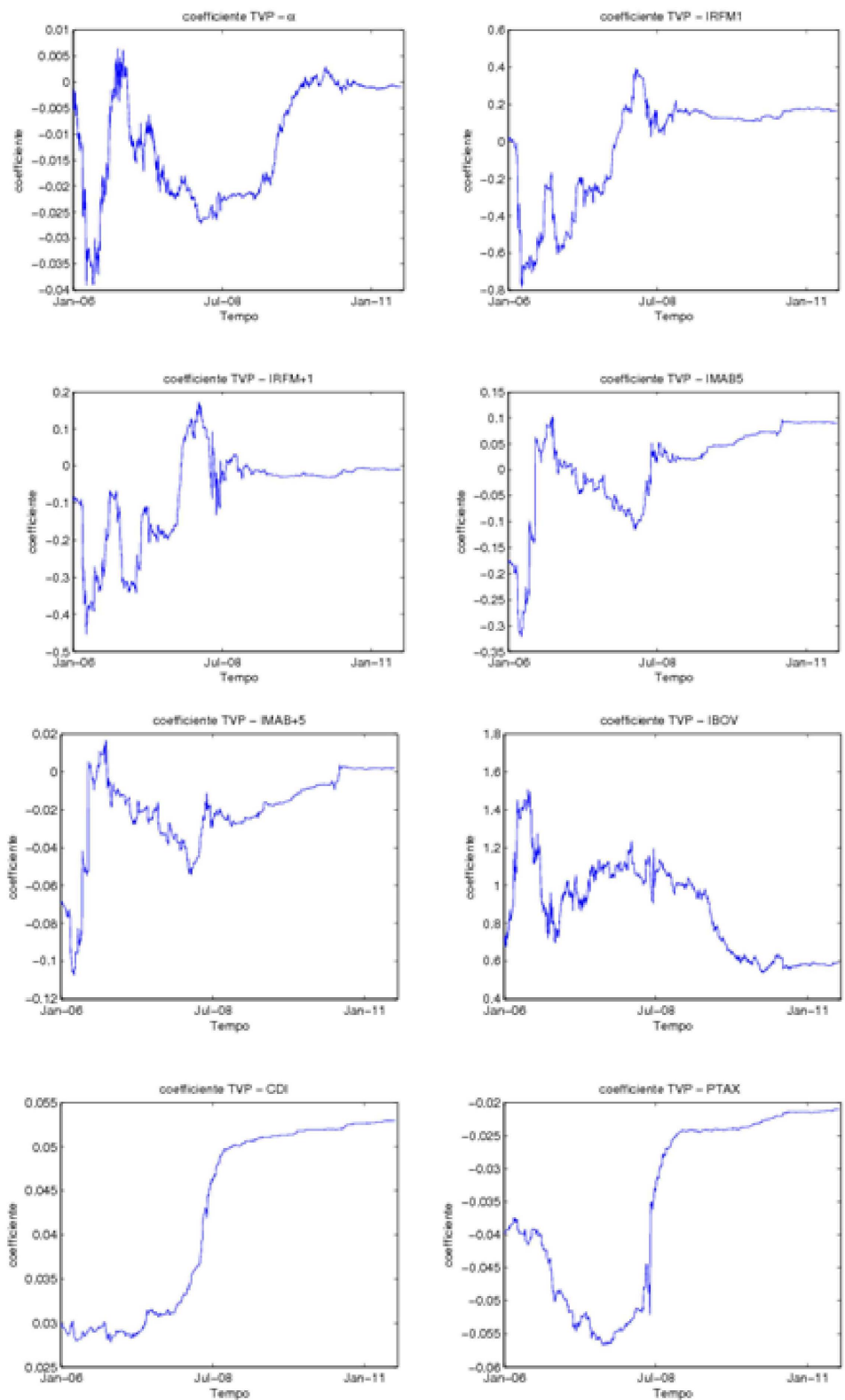

Fonte: Elaboração própria. 
Observando a variaçăo no parâmetro estimado referente à exposiçăo ao mercado de açōes, representado pelo índice Ibovespa, percebe-se que é a classe de ativo na qual os gestores possuem estratégias mais ativas, ora aumentando, ora diminuindo a alocação nesse fator de risco. De fato, é reconhecido no mercado financeiro brasileiro que os fundos multimercados tiveram seu desempenho fortemente relacionado ao mercado ações por muito tempo. Segundo um estudo realizado pelo HSBC Global Asset Management, por exemplo, a forte queda do Ibovespa, em 2008, afetou fortemente a rentabilidade da indústria de fundos multimercados. $O$ estudo mostra ainda que a partir disso muitos gestores alteraram sua forma de gestão, buscando diminuir a alocação dos fundos multimercados em renda variável. Segundo esse estudo, em junho de 2009, a correlação entre esses fundos e o lbovespa estava em torno de 0.84, e, em meados de 2011, era de aproximadamente 0.52 (VALOR ECONÔMICO, 2011).

Além disso, com o objetivo de medir a persistência ${ }^{13}$ do estilo dos fundos no tempo, é calculado o coeficiente de autocorrelação para a série de pesos de cada fator. ${ }^{14}$ Pode-se observar, na Tabela 7, que apresenta as persistências das exposições dos fundos aos fatores de risco por período e também as estatísticas descritivas que auxiliam na análise das medidas de persistência, que a persistência dos pesos dos fatores cai consideravelmente quando se considera uma defasagem de 63 dias, com destaque para a exposição ao Ibovespa, coeficiente que apresenta maior queda na persistência ao passar do horizonte de 21 para 63 dias. Esse resultado corrobora o observado anteriormente: os gestores possuem estratégias mais ativas da carteira de açōes, isto é, alteram o percentual de exposiçăo nesse fator de risco mais recorrentemente que nos demais fatores.

13 Brown et al. (1999) estudam a persistência nas exposiçöes e performance de 399 fundos de investimentos off shore para o período de 1989 a 1995.

Ver, por exemplo, Tsay (2010). 
Tabela 7 - Persistência das exposições aos fatores de risco por período

\begin{tabular}{|c|c|c|c|c|c|c|c|c|c|}
\hline & & $\alpha$ & IRF-M1 & IRF-M1+ & IMA-B5 & IMA-B5+ & IBOV & CDI & PTAX \\
\hline \multirow{5}{*}{$\rho(1)$} & Média & 0,925 & 0,966 & 0,979 & 0,907 & 0,800 & 0,962 & 0,814 & 0,791 \\
\hline & Mediana & 0,938 & 0,982 & 0,986 & 0,923 & 0,835 & 0,976 & 0,939 & 0,884 \\
\hline & Desvio padrão & 0,057 & 0,040 & 0,030 & 0,076 & 0,136 & 0,045 & 0,254 & 0,220 \\
\hline & Mínimo & 0,430 & 0,623 & 0,635 & 0,465 & 0,265 & 0,490 & $-0,157$ & $-0,089$ \\
\hline & Máximo & 0,995 & 0,999 & 0,999 & 0,998 & 0,998 & 0,998 & 0,999 & 0,998 \\
\hline \multirow{5}{*}{$\rho(5)$} & Média & 0,740 & 0,876 & 0,913 & 0,651 & 0,469 & 0,856 & 0,680 & 0,592 \\
\hline & Mediana & 0,782 & 0,927 & 0,941 & 0,690 & 0,466 & 0,905 & 0,759 & 0,668 \\
\hline & Desvio padrão & 0,163 & 0,130 & 0,111 & 0,256 & 0,251 & 0,140 & 0,272 & 0,275 \\
\hline & Mínimo & 0,214 & $-0,005$ & $-0,097$ & $-0,242$ & $-0,154$ & 0,163 & $-0,006$ & $-0,044$ \\
\hline & Máximo & 0,972 & 0,993 & 0,994 & 0,987 & 0,989 & 0,991 & 0,995 & 0,991 \\
\hline \multirow{5}{*}{$\rho(21)$} & Média & 0,479 & 0,716 & 0,765 & 0,455 & 0,271 & 0,626 & 0,586 & 0,542 \\
\hline & Mediana & 0,482 & 0,782 & 0,820 & 0,474 & 0,180 & 0,703 & 0,638 & 0,601 \\
\hline & Desvio padrão & 0,230 & 0,193 & 0,178 & 0,289 & 0,248 & 0,237 & 0,271 & 0,268 \\
\hline & Mínimo & $-0,164$ & $-0,021$ & 0,011 & $-0,061$ & $-0,104$ & $-0,166$ & $-0,016$ & $-0,015$ \\
\hline & Máximo & 0,890 & 0,953 & 0,957 & 0,945 & 0,948 & 0,954 & 0,976 & 0,959 \\
\hline \multirow{5}{*}{$\rho(63)$} & Média & 0,173 & 0,471 & 0,497 & 0,314 & 0,206 & 0,299 & 0,453 & 0,416 \\
\hline & Mediana & 0,163 & 0,519 & 0,534 & 0,278 & 0,126 & 0,293 & 0,472 & 0,443 \\
\hline & Desvio padrão & 0,223 & 0,194 & 0,223 & 0,238 & 0,210 & 0,235 & 0,265 & 0,242 \\
\hline & Mínimo & $-0,312$ & $-0,091$ & $-0,125$ & $-0,064$ & $-0,038$ & $-0,193$ & $-0,073$ & $-0,014$ \\
\hline & Máximo & 0,715 & 0,844 & 0,870 & 0,864 & 0,877 & 0,854 & 0,915 & 0,880 \\
\hline
\end{tabular}

Fonte: Elaboração própria.

A Figura 2 apresenta o coeficiente $R^{2}$ de cada um dos fundos considerados na amostra. O primeiro gráfico traz o $R^{2}$ para o modelo estimado através do filtro de Kalman, já o segundo apresenta o $R^{2}$ do modelo estimado por OLS.

Figura $2-R^{2}$ ajustado da análise de estilo
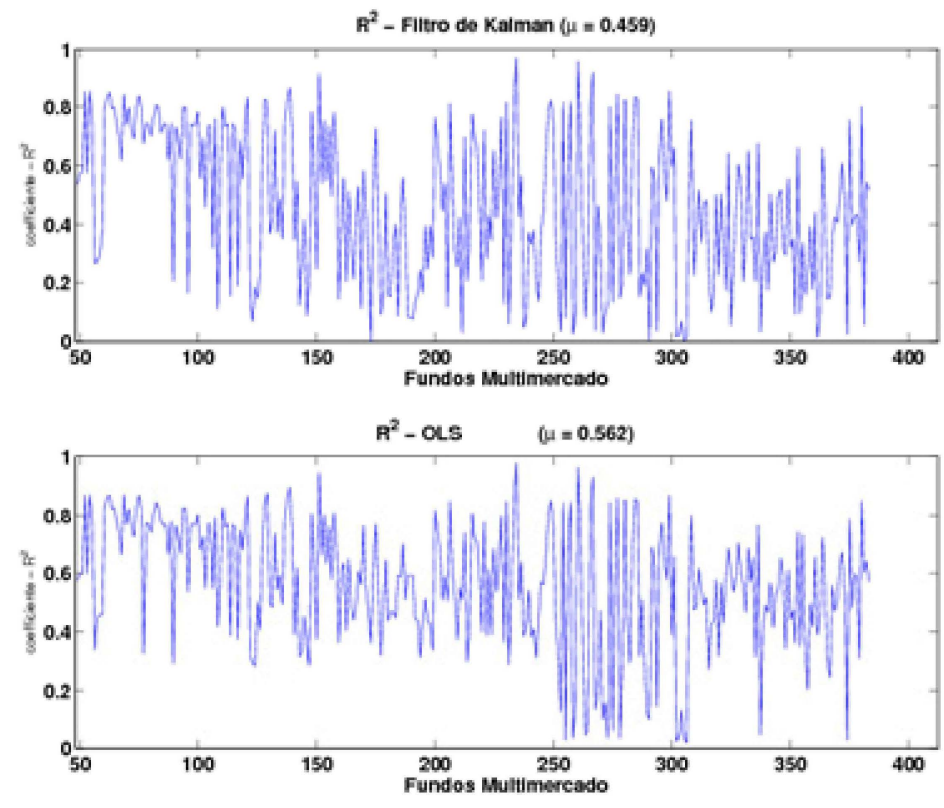

Fonte: Elaboração própria. 
A Figura 2 mostra o $R^{2}$ ajustado do modelo estimado através do filtro de Kalman, quando os pesos dos fatores variam ao longo do tempo, e do modelo estimado por OLS. Na abordagem com parâmetros variando no tempo, o $R^{2}$ ajustado médio é de 0.46 , indicando elevado poder explicativo da análise de estilo. No caso da estimação por OLS, o $R^{2}$ médio é ainda maior, 0.56 . Assim, são encontradas evidências de que a análise de estilo pode explicar aproximadamente $50 \%$ da variância dos retornos dos fundos multimercados brasileiros, sendo o restante atribuído à habilidade dos gestores.

Os resultados encontrados evidenciam a importância da análise de estilo como uma ferramenta útil através da qual investidores, e até mesmo gestores, podem obter uma primeira impressão a respeito do histórico de estilo do fundo e de a quais fatores de risco estarão expostos. Também reforça a importância de se considerar a dinâmica na gestão dos fundos multimercados em aplicações empíricas da análise de estilo a essa categoria de fundos.

\section{Considerações Finais}

Os fundos de investimento multimercados abrangem uma ampla gama de estratégias com diferenças radicais em termos de risco. Portanto, a análise de estilo baseada nos retornos é uma ferramenta útil e rapidamente aplicável por investidores a fim de se obter uma primeira impressão a respeito da filosofia de investimento dos fundos. Através da RBSA é possivel inferir as exposiçöes ao risco dos gestores de fundos e ajudar na determinação de um benchmark adequado para avaliar seu desempenho (SWINKELS; SLUIS, 2006). Empiricamente, existe ampla evidência de que o estilo de investimento de um fundo varia ao longo do tempo, o que dificulta a estimação de estilo através de modelo de regressão padrão.

Pesquisas recentes envolvendo análise de hedge funds e fundos mútuos têm destacado a importância de se levar em conta a natureza dinâmica da exposição aos fatores de risco desses veículos de investimento administrados ativamente. Várias abordagens são propostas na literatura, incluindo técnicas de regressão ótimas para identificar pontos de quebra e modelagem das exposiçōes aos fatores de risco como fatores latentes não observados, técnica empregada neste estudo para capturar as variaçôes temporais nas exposições dos fundos multimercados brasileiros aos principais fatores de risco.

Neste trabalho, inicialmente a RBSA generalizada é implementada através de estimação por OLS. Para se obter mais informaçóes sobre a estrutura dinâmica dos pesos dos fatores de estilo e exposiçāo ao risco, a amostra é dividida em quatro partes e o modelo é estimado para cada subamostra. Geralmente, para se levar em conta que as exposiçöes aos fatores variam ao longo do tempo, se utiliza um esquema de estimação rolling-window. Porém, nesses casos, a escolha do tamanho da 
janela é geralmente ad hoc, sem motivaçăo estatística. A alternativa considerada neste artigo para modelar explicitamente as variaçōes nas exposições ao longo do tempo consiste na estimação através do filtro de Kalman. Com essa abordagem, a amostra inteira é usada de forma eficiente para se obter estimativas das exposições em cada ponto do tempo. Este é o primeiro estudo empírico que aplica essas técnicas com foco especial na indústria brasileira de fundos multimercados, usando uma ampla base de fundos.

Os resultados empíricos mostram que o mais significativo fator de risco ao qual os fundos multimercados brasileiros estão expostos refere-se ao mercado de ações, com esse fator representando um peso médio de aproximadamente $60 \%$. Em relação à exposição dos fundos ao mercado de renda fixa, em geral esses fatores juntos (IMA-B, IRF-M e CDI) representam um peso médio de aproximadamente $25 \%$. A análise de estilo pode explicar até $50 \%$ da variância dos retornos fundos multimercados. A parcela da variância inexplicada pode ser atribuída à habilidade dos gestores. Os resultados evidenciam a importância de se considerar explicitamente a dinâmica na exposição aos fatores de risco em aplicações de análise de estilo a fundos multimercados, similar aos resultados encontrados por Bollen e Whaley (2009) e Jawadi e Khanniche (2012) em aplicações de RBSA a dados de hedge funds de outros países. Além disso, a abordagem com filtro de Kalman capta as importantes mudanças na exposição dos fundos multimercados aos fatores de risco decorrentes da recente crise financeira global (2008-2009).

Finalmente, se observa que grande parte da dinâmica das exposições dos fundos multimercados está associada a estratégias envolvendo o mercado de açōes e que, nos últimos anos, os gestores de fundos no Brasil têm diminuído sua exposiçăo direcional nesse mercado. Vale ressaltar a importância desse tipo de investigação, principalmente para a indústria de fundos brasileira, na qual não existem benchmarks claramente definidos. Dessa forma, a análise de estilo baseada nos retornos se coloca como uma ferramenta poderosa para o investidor identificar de forma simples os fatores de risco aos quais cada fundo está exposto e, assim, decidir por aquele que for mais adequado ao seu estilo.

\section{Referências}

ACKERMANN, C.; MCENALLY, R.; RAVENSCRAFT, D. The performance of hedge funds: Risk, return, and incentives. Journal of Finance, v. 54, n. 3, p. 833-874, June 1999.

AGARWAL, V.; NAVEEN D. D.; NAIK, N. Y. Role of managerial incentives and discretion in hedge fund performance. Journal of Finance, v. 64, n. 5, p. 2221-2256, Oct. 2009.

AGARWAL, V.; NAIK, N. Y. Generalyzed style analysis of hedge funds. Journal of Asset Management, v. 1, n. 1, p. 93-109, 2000. 
ALMEIDA, A. R.; MENDES, B. V.; NAZARETH, M. Análise de estilo robusta. In: ENCONTRO BRASILEIRO DE FINANÇAS, 7., 2007, São Paulo. Anais...São Paulo: Sociedade Brasileira de Finanças, 2007.

ALVES JÚNIOR, A. J. Fundos mútuos de investimentos no brasil. a expansăo da indústria nos anos 1990 e perspectivas para o futuro. CEPAL, 2003. (Textos para discussăo LC/BRS/R.143).

ASSOCIAÇÃO BRASILEIRA DAS ENTIDADES DOS MERCADOS FINANCEIROS E DE CAPITAIS. 2012. Disponivel em: <hitp://www.anbima.com.br>. Acesso em: 04 maio 2013.

ASSOCIAÇĀO NACIONAL DOS BANCOS DE INVESTIMENTO. Auto-regulação dos fundos de investimento. 2011. Disponivel em: <http:/www.anbid.com.br>. Acesso em: 03 maio 2012.

GAURAV S. A.; HARRY M. K. Stocks, bonds and hedge funds: not a free lunch! Journal of Portfolio Management, v. 30, n. 2, p. 113-120, 2003.

ANSON, M. J. P. Symmetric performance measures and asymmetric trading strategies. Journal of Alternative Investments, v. 5, n. 1, p. 81-85, 2002.

BARBERIS, N.; SHLEIFER, A. Style investing. Journal of Financial Economics, v. 68, n. 2, p. 161-191, 2003.

BODSON, L.; COẼN, A.; HÜBNER, G. Dynamic hedge fund style analysis with errors-invariables. Joumal of Financial Research, v. 33, n. 3, p. 201-221, 2010.

BOLLEN, N. P. B.; WHALEY, R. E. Hedge fund risk dynamics: implications for performance appraisal. Journal of Finance, v. 64, n. 2, p. 985-1035, Apr. 2009.

BROWN, S. J.; GOETZMANN, W.; IBBOTSON, R. G. Offshore hedge funds: survival and performance, 1989-95. The Journal of Business, v. 72, n. 1, p. 91-117, Jan. 1999.

BROWN, S. J. Hedge funds: omniscient or just plain wrong. Pacific-Basin Finance Journal, v. 9, n. 4, p. 301-311, Aug. 2001.

BROWN, S. J.; GOETZMANN, W. Hedge funds with style. The Journal of Portfolio Management, v. 1, n. 1, p. 101-112, 2003.

Mutual fund styles. Joumal of Financial Economics, v. 43, n. 3, p. 373-399, 1997.

CHAN, L.; CHEN, H.; LAKONISHOK, J. On mutual fund investment styles. Review of Financial Studies, v. 15, n. 5, p. 1407-1437, 2002.

CHRISTOPHERSON, J.; TRITTIN, D. An equity style classification sistem. In: COGGIN, T. D.; FABOZZI, F. J. The Handbook of Equity Syle Management. New Hope: Fabozzi and Associates Publishing, 1995. p. 171-194.

CORIELLI, F; MEUCCI, A. Pitfalls in linear models for style analysis. Statistical Methods 8 Applications, v. 13, n. 1, p. 105-129, 2004.

DIBARTOLOMEO, D.; WITKOWSKI, E. Mutual fund misclassification: evidence based on style analysis. Financial Anabyst Joumal, v. 53, n. 5, p. 32-43, 1997. 
DOR, A. B.; JAGANNATHAN, R. Understanding mutual fund and hedge fund styles using return based style analysis. Journal of Investment Management, v. I, n. I, p. 97-137, 2003.

FUNG, W.; HSIEH, A. D. Empirical characteristics of dynamic trading strategies: the case of hedge funds. Review of Financial Studies, v. 10, n. 2, p. :275-302, 1997.

. D. Asset-based style factors for hedge funds. Analyst Journal, v. 58, n. 5, p. 16-27, 2002.

FUNG, W. et al. Hedge funds: performance, risk, and capital formation. Journal of Finance, v. 63, n. 4, p. $1777-1803,2005$.

GIBSON, R.; GYGER, S. The style consistency of hedge funds. European Financial Management, v. 13, n. 2, p. 287-308, 2007.

HORST, J. D.; NIJMAN, T. E.; DEROON, F. A. Evaluating style analysis. Journal of Empirical Finance, v. 11, n. 1, p. 29-53, Jan. 2004.

AGANNATHAN, R..; MALAKHOV, A.; NOVIKOV, D. Do hot hands exist among hedge fund managers? an empirical evaluation. Joumal of Finance, v. 65, n. 1, p. 217-255, Feb. 2010.

JAWADI, R.; KHANNICHE, S. Modeling hedge fund exposure to risk factors. Economic Modelling, v. 29, n. 4, p. 1003-1018, 2012.

KOOPMAN, S. J. Exact initial kalman filtering and smoothing for nonstationary time series models. Joumal of the American Statistical Association, v. 92, n. 440, p. 1630-1638, 1997.

KOSOWSKI, R..; NAIK, N. Y.; TEO, M. Do hedge funds deliver alpha? a bayesian and bootstrap analysis. Journal of Financial Economics, v. 84, n. 1, p. 229-264, 2007.

KUGLER, P.; HENN-OVERBECK, J.; ZIMMERMANN, H. Style consistency of hedge fund indexes across providers. Applied Financial Economics, v. 20, n. 5, p. 355-369, 2010.

LAU, W.R. An integrated framework for style analysis: how is it useful to malaysian equity trust investors? Managerial Finance, v. 33, n. 2, p. 122-141, 2007.

MAMAYSKY, H.; SPIEGEL, M.; ZHANG, H. Estimating the dynamics of mutual fund alphas and betas. Review of Financial Studies, v. 21, n. I, p. 233-264, 2008.

MARQUES, R.; PIZZINGA, A.; VEREDA, L. Restricted kalman filter applied to dynamic style analysis of actuarial funds. Applied Stochastic Models in Business and Industry, v. 28, n. 6, p. 558-570, Nov/Dec. 2012.

MARTIN, E. Does hedge fund performance persist? overview and new empirical evidence. European Financial Management, v. 15, n. 2, p. 133-157, 2009.

MITCHELL, M.; PULVINO, T. Characteristics of risk and return in risk arbitrage. Journal of Finance, v. 56, n. 6, p. 2135-2175, Dec. 2001.

OTTEN, R.; BAMS, D. How to measure mutual fund performance: economic versus statistical relevance. Accounting and Finance, v. 44, n. 2, p. 203-222, 2004.

PATTARIN, F.; PATERLINI, S.; MINERVA, T. Clustering financial time series: an application to mutual funds style analysis. Computational Statistics \& Data Anahysis, v. 47, p. 353-372, 2004. 
PATTON, A. J.; RAMADORAI, T. On the high-frequency dynamics of hedge fund risk exposures. London: Centre for Economic Policy Research, July 2011. (CEPR Discussion Papers, n. 8479).

PATTON, A. J. Are "market neutral" hedge funds really market neutral? Review of Financial Studies, v. 22, n. 7, p. 2295-2330, 2009.

PIZZINGA, A.; VEREDA, L.; FERNANCES, C. A dynamic style analysis of exchange rate funds: the case of brazil at the 2002 election. Advances and Applications in Statistical Sciences, v. 6, n. 1, p. 111-135, 2011.

PIZZINGA, A.; ARTHERINO, C.; FERNANCES, C. Semi-strong dynamic style analysis with time-varying selectivity measurement: applications to brazilian exchange-rate funds. Applied Stochastic Models in Business and Industry, v. 24, n. 1, p. 3-12, Jan.Feb. 2008.

PIZZINGA, A.; FERNANCES. Análise dinâmica de estilo: monitoramento contínuo da política de gestão de fundos de investimento. Resenha BMEF, p. 31-49, abr. 2005.

State space models for dynamic style analysis of portfolios. Brazilian Review of Econometrics, v. 26, n. 1, p. 31-66, 2006.

POJARLIEV, M.; LEVICH, R. M. Trades of the living dead: style differences, style persistence and performance of currency fund managers. Journal of International Money and Finance, v. 29, n. 8, p. 1752-1775, Dec. 2010.

SHARPE, W. F. Asset allocation: management style and performance measurement. Joumal of Portfolio Manegement, v. 18, n. 2, p. 7-19, 1992.

p. 59-69, 1998 .

Determining a fund's effective asset mix. Investment Management Joumal, v. 2, n. 6,

SWINKELS, L.; SLUIS, P. V. Return-based style analysis with time-varying exposures. European Journal of Finance, v. 12, n. 6-7, p. 529-552, 2006.

TRZCINKA, C. Equity styles classifications: comment. Journal of Portfolio Manegement, v. 21, n. 3, p. 44-46, 2001.

VALOR ECONÔMICO. Descolados da Bolsa. Jornal Valor Econômico, 2011. Disponível em: < http://ww2.anefac.com.br/Pages/ReaderPage.aspx?id=4882 > . Acesso em: 03 maio 2012.

VARGA, G.; VALLI, M. Análise de estilo baseada no retorno. Revista da ANBID, v. 9, dez. 1998.

VESTERGREN, D. Asset allocation within Swedish mutual funds. Sweden: Stockholm School of Economics, 2009. (Master's thesis in finances)

WENG, H.; TRÜCK, S. Style analysis and value-at-risk of asia-focused hedge funds. PacificBasin Finance Joumal, v. 19, n. 5, p. 491-510, Nov. 2011. 


\section{Apêndice A - Classificação dos Fundos Multimercados}

Os multimercados sāo fundos que buscam retorno no longo prazo através de investimentos em diversas classes de ativos (renda fixa, renda variável, câmbio, ações, etc.). Sua classificação se baseia nas estratégias adotadas pelos gestores para atingir os objetivos dos fundos. Segundo a Associação Brasileira das Entidades dos Mercados Financeiro e de Capitais (2010), podem se classificar em:

a) balanceados: fundos que buscam retorno no longo prazo através de investimento em diversas classes de ativos (renda fixa, açōes, câmbio, etc.). Esses fundos utilizam uma estratégia de investimento diversificada e deslocamentos táticos entre as classes de ativos ou estratégia explícita de rebalanceamento de curto prazo;

b) capital protegido: fundos que buscam retornos em mercados de risco procurando proteger, parcial ou totalmente, o principal investido. Não admitem alavancagem.

c) multimercados estratégia específica: fundos que adotam uma estratégia de investimento que implique riscos específicos, tais como commodities e futuro de índice. Admitem alavancagem;

d) multimercados juros e moedas: fundos que buscam retorno no longo prazo através de investimentos em ativos de renda fixa, admitindo estratégias que impliquem risco de juros, risco de índice de preço e risco de moeda estrangeira. Excluem estratégias que impliquem exposiçâo de renda variável (ações, etc.). Admitem alavancagem;

e) long and short (direcional): fundos que fazem operaçöes de ativos e derivativos ligados ao mercado de renda variável, montando posiçōes compradas e vendidas. O resultado deve ser proveniente, preponderantemente, da diferença entre essas posiçōes;

f) long and short (neutro): fundos que fazem operaçôes de ativos e derivativos ligados ao mercado de renda variável, montando posições compradas e vendidas, com o objetivo de manter a exposição neutra ao risco do mercado acionário;

g) multimercados macro: fundos que realizam operaçōes em diversas classes de ativos, definindo as estratégias de investimento baseadas em cenários macroeconômicos de médio e longo prazo, atuando de forma direcional;

h) multimercados multiestratégia: fundos que podem adotar mais de uma estratégia de investimento, sem o compromisso declarado de se dedicar a uma em particular. Admitem alavancagem;

i) multimercados multigestor: fundos que têm por objetivo investir em mais de um fundo, geridos por gestores distintos. A principal competência envolvida consiste no processo de seleção de gestores; 
j) multimercados trading: fundos que concentram as estratégias de investimento em diferentes mercados ou classes de ativos, explorando oportunidades de ganhos originados por movimentos de curto prazo nos preços dos ativos.

\section{Apêndice B - Índices de Mercado: Fatores de Risco}

Os fatores de risco representados por índices de mercado utilizados neste estudo são:

a) IRF-M1 e IRF-MI +: para risco da curva de juros prefixada;

b) Ibovespa: para risco do mercado de ações;

c) IMA-B5 e IMA-B5+: para risco de inflação;

d) dólar-PTAX: para risco de taxa de câmbio;

e) CDI: para fator livre de risco.

No caso da classe de ativos exposta ao mercado de ações, o lbovespa é um índice bastante abrangente, além de ser o mais utilizado no mercado financeiro, portanto, é considerado suficiente para representar essa classe de ativos. O CDI como fator livre de risco também já é amplamente aceito, além de ser utilizado como o benchmark oficial da indústria de fundos de renda fixa no Brasil.

No caso da classe de ativos exposta à variação cambial, o dólar é a moeda estrangeira mais negociada no mercado à vista e também a com a maior liquidez no mercado futuro da BMËF. Por essa razâo, reflete bem a maior parte das estratégias envolvendo moedas estrangeiras nos fundos multimercados. Para representar a variaçăo desse fator de risco, foi escolhida a taxa PTAX.

Para o mercado de renda fixa, a divulgaçāo de índices é recente e vem se aprimorando nos últimos anos com a divulgação do Índice de Mercado Anbima (IMA) . Com o objetivo de atender às necessidades dos diversos tipos de investidores, o IMA envolve uma familia de subíndices que representa a evolução, a preços de mercado, dos títulos públicos de acordo com seus indexadores (ASSOCIAÇÃO BRASILEIRA DAS ENTIDADES DOS MERCADOS FINANCEIRO E DE CAPITAIS, 2012). A seguir seguem os subíndices desenvolvidos e apresentados pelo $I M A$ :

a) títulos prefixados (NTN-F e LTN) são representados pelo IRF-M;

b) títulos indexados ao IPCA (NTN-B) representados pelo IMA-B;

c) títulos indexados ao IGPM (NTN-C) pelo IMA-C;

d) títulos pós-fixados (LFT) pelo IMA-S.

A utilização desses índices como referência (benchmark) para a indústria de fundos de renda fixa no Brasil vem crescendo significativamente, sendo a utilização de tais índices cada vez mais difundida entre os participantes do mercado. Assim, para representar o risco da curva de juros prefixada, foi utilizado o IRF-M e, para representar a curva de cupom de inflação, o IMA-B. Quanto ao IMA-C, a dívi- 
da atrelada ao IGP-M vem perdendo relevância devido à baixa liquidez observada nesse segmento, e o IMA-S é um índice muito próximo ao $\mathrm{CDI}$, portanto nenhum dos dois índices foi inserido no estudo.

Ainda em relação ao IRF-M e ao IMA-B, existem mais dois subíndices divulgados pela Anbima, que são calculados com base nos prazos de vencimento dos seus componentes:

a) IRF-M1: contém os títulos com prazo inferior a um ano;

b) IRF-MI + contém os títulos com prazo igual ou superior a um ano;

c) IMA-B5: contém os títulos com prazo inferior a cinco anos;

d) IMA-B5+: contém os tútulos com prazo igual ou superior a cinco anos.

A definição dos prazos de cada índice foi realizada pelo fórum responsável pelo desenvolvimento da metodologia e acompanhamento dos índices, o qual defende que o prazo de até cinco anos concentra os vencimentos mais líquidos no caso do IMA-B. No caso do IRF-M, o prazo de um ano foi escolhido porque a carteira dos títulos prefixados no Brasil possui um perfil de maturidade menor (ASSOCIAÇĀO BRASILEIRA DAS ENTIDADES DOS MERCADOS FINANCEIRO E DE CAPITAIS, 2012).

Recebido em: 19/03/2014. Aceito em: 07/08/2014. 